\title{
Causes of Heart Failure in Patients Admitted to Al-Yarmook Teaching Hospital During One Year (2015)
}

\author{
Ahmed Adil Al-Saeedi", Emad Kareem Luaibi, Malallah Akreem Amwer, \\ Abdulhameed Al-Qaseer
}

Department of Medicine, AL Mustansiriya University, Baghdad, Iraq

\section{Email address:}

dr_ahmed_ad2004@yahool.com (A. A. Al-Saeedi), emadkareem72@yahool.com (E. K. Luaibi), drmalallahkareem@yahoo.com (M. A. Amwer), drhameed1960@gmaill.com (A. Al-Qaseer)

${ }^{*}$ Corresponding author

\section{To cite this article:}

Ahmed Adil Al-Saeedi, Emad Kareem Luaibi, Malallah Akreem Amwer, Abdulhameed Al-Qaseer. Causes of Heart Failure in Patients Admitted to Al-Yarmook Teaching Hospital During One Year (2015). European Journal of Preventive Medicine. Vol. 8, No. 3, 2020 , pp. $30-35$. doi: 10.11648/j.ejpm.20200803.12

Received: March 31,2020; Accepted: April 14, 2020; Published: May 12, 2020

\begin{abstract}
Heart failure (HF) is a clinical syndrome in which abnormalities of cardiac function are responsible for the inability of the heart to pump blood at an output sufficient to meet the requirements of metabolizing tissues. This study aims to determine the possible causes of heart failure in patients admitted to medical and coronary care unit wards of Al-Yarmook Teaching Hospital. The study was conducted in the medical wards and CCU of Al-Yarmook Teaching Hospital during the year 2015 (from January $1 \mathrm{st}$ till December $31 \mathrm{st}$ ). It is a cross-sectional descriptive study. The patients were randomly selected and taken into account after the clinical diagnosis of heart failure and meeting the Framingham's Criteria for diagnosing heart failure. Then a study form was filled with the patients' data after having the patient's consent. The study shows that ischemic heart diseases were the most prevalent cause of heart failure with $56.58 \%$. Hypertensive heart disease and dilated cardiomyopathy being the second most prevalent single cause with $9.21 \%$ for each. Valvular heart disease was less prevalent with only $5.26 \%$ while anemia, diabetes and constrictive pericarditis were the least prevalent causes with only $1.23 \%$ for each. Multiple causes accounts $15.79 \%$ of the total causes of heart failure in this study. As Heart Failure is a growing health problem. Primary and secondary preventive measures should be applied and followed up by the health services to reduce incidence of heart failure. Biomarkers such as BNP and Pro-BNP are essential in diagnosis and follow up of cases with heart failure in hospital.
\end{abstract}

Keywords: Heart Failure, Causes, IHD, Framingham Criteria

\section{Introduction}

\subsection{Definition}

Heart failure (HF) is a clinical syndrome in which abnormalities of cardiac function are responsible for the inability of the heart to pump blood at an output sufficient to meet the requirements of metabolizing tissues. [1]

Causes of heart failure: [1]

1. Ischemic heart disease: is the most common cause of heart failure [1-4].

2. Systemic hypertension: it remains a second important cause of CHF [1-3].

3. Diabetes mellitus: [1-3] increased incidence of congestive heart failure in diabetic subjects irrespective of coronary heart disease and hypertension [5-7].

4. Valvular heart disease: As in stenosis or regurgitation of aortic and mitral valves [1-3].

5. Non-ischemic dilated cardiomyopathy: alcoholic cardiomyopathy, viral myocarditis and idiopathic cardiomyopathy, etc [1-3].

6. Cor-pulmonale: due to pulmonary hypertension caused by diseases affecting the lung or its vasculature [1-3].

7. Peripartum heart disease: Cardiac failure in the last trimester or within five months of delivery [8].

8. Familial/genetic disorders: Duchenne's, Becker's, and limb girdle muscular dystrophies [1-3].

9. Infiltrative disorders (Amyloidosis, sarcoidosis) and 
Storage diseases (hemochromatosis) [1-3].

10. Constrictive pericarditis \& Tamponade. [1-3].

11.High-output States: (in Thyrotoxicosis), (beriberi), etc...[1-3].

\subsection{Epidemiology}

Heart failure is an expanding problem worldwide, with more than 20 million people affected [2]. The overall prevalence of $\mathrm{HF}$ in the adult population in developed countries is $2 \%$ [2]. Heart Failure affects $6-10 \%$ of people over the age of 65 years $[9,10]$.

Classification of Heart Failure: Clinically it is classified as:

1. Acute decompensated heart failure: [1]

2. Chronic Heart Failure: [1]

i. Left-Sided and Right-Sided Heart Failure.

ii. Heart Failure with Preserved Ejection Fraction.

Functionally, Heart Failure is classified according to the New York Heart Association (NYHA) classification, from Class I to Class IV [11].

Diagnosis of Heart Failure [1].

The diagnosis of heart failure is straightforward when a patient presents with classic symptoms and accompanying physical findings in addition to blood tests and neurohormonal tests (BNP and Pro-BNP) along with ECG, chest X-ray and echo study may confirm the diagnosis and denote the possible etiology [11-12].

\section{Aim of Study}

To determine the possible causes of heart failure in patients admitted to the medical wards and coronary care unit of Al-Yarmook Teaching Hospital in one year.

\section{Methods of Study}

The study was conducted in the medical wards and CCU of Al-Yarmook Teaching Hospital during the year 2015 (from January $1^{\text {st }}$ till December $31^{\text {st }}$ ). It is a cross-sectional and descriptive study. The patients were randomly selected and taken into account after the clinical diagnosis of heart failure and meeting the Framingham's Criteria for diagnosing heart failure. Then a study form (Appendix 1) was filled with the patients' data after having the patient's consent.

The interview and clinical examination was performed by the attending physician, the blood tests were made in Al-Yarmook Teaching Hospital's Laboratory after taking the blood samples from the selected patients, and the ECG was done in the emergency department or the medical wards or CCU. Chest X-Ray was done in the radiology department and the Echo study was made in Al-Yarmook Teaching Hospital's echo department by a specialist cardiologist and the cardiologist conclusion for the etiology of heart failure is taken in account.

Inclusion Criteria includes age older than 18 years old and meeting two major or one major and two minor criteria of the Framingham's criteria for diagnosing heart failure.
Exclusion criteria is that the patient does not meet at least two major or one major and two minor of the Framingham's criteria for diagnosing heart failure or the serum level of BNP is less than $100 \mathrm{pg} / \mathrm{ml}$.

The Framingham criteria for the diagnosis of heart failure consists of the concurrent presence of either 2 major criteria or 1 major and 2 minor criteria [13].

Major criteria include the following;

1. Paroxysmal nocturnal dyspnea

2. Weight loss of $4.5 \mathrm{~kg}$ in 5 days in response to treatment.

3 . Neck vein distention of $5 \mathrm{~cm}$ height or more considered elevated jugular venous pressure [14].

4. Rales it indicate pulmonary interstitial edema [14].

5. Acute pulmonary edema.

6. Hepatojugular reflux.

7. S3 gallop.

8. Radiographic cardiomegaly cardiothoracic ratio on postero-anterior chest X-Ray film is more than $50 \%$.

Minor criteria are as follows;

1. Nocturnal cough.

2. Dyspnea on ordinary exertion.

3. Pleural effusion.

4. Tachycardia (rate of $120 \mathrm{bpm}$ ).

5. Bilateral ankle edema.

Patient is said to have hypertension when s/he has history of hypertension and on antihypertensive medications and/or blood pressure measurement is more than $140 \mathrm{mmHg}$ systolic and $90 \mathrm{mmHg}$ diastolic [2].

Diabetes mellitus is diagnosed by fasting plasma glucose $>126 \mathrm{mg} / \mathrm{dl}, 2$ hours postprandial plasma glucose level of $>200 \mathrm{mg} / \mathrm{dl}$ and $\mathrm{HbA} 1 \mathrm{C}>6.5 \%$ or the random plasma glucose level is $>200 \mathrm{mg} / \mathrm{dl}$ with symptoms of diabetes like polydipsia, polyuria and polyphagia [2].

Electrocardiography (ECG) is done for all patients looking for features suggesting ischemia (ST segment depression or elevation, $\mathrm{T}$ wave flattening or inversion or the presence of pathological Q wave or any conduction defect), or ventricular hypertrophy (prominent $\mathrm{R}$ wave in $\mathrm{V}_{1}$ and a persistent deep $\mathrm{S}$ in $V_{6}$ for right ventricular hypertrophy, and the reverse in left ventricular hypertrophy) [2,15].

Echocardiography; non-invasive cardiac imaging is a crucial part of the diagnosis and evaluation of heart failure. The most useful procedure is transthoracic echocardiography, which provides a quantitative assessment of LV function; in the presence of appropriate symptoms and signs, it can confirm the presence of heart failure resulting from systolic dysfunction or indicate whether the patient has heart failure with preserved systolic function. The echocardiogram also provides a wealth of additional valuable information, including assessment of LV and RV size and regional wall motion (as an indicator of prior MI), evaluation of the heart valves, and diagnosis of LV hypertrophy. Particularly valuable are quantitative measurements of pulmonary artery and central venous pressures $[1,16]$.

Hypertensive heart disease is diagnosed by history of hypertension with ECG finding of left ventricular hypertrophy ( $S$ wave in $V_{1}$ plus $R$ wave in $V_{6}>35 \mathrm{~mm}$ ) and echo features of 
left ventricular hypertrophy (left ventricular posterior wall or interventricular septum diameter $>12 \mathrm{~mm}$ in $2 \mathrm{D}$ echo) [15, $16]$.

Ischemic heart failure is diagnosed if the subject had either positive history of typical angina or acute myocardial infarction, history of positive PCI or CABG and/or typical ECG abnormalities of acute myocardial infarction or myocardial ischemia, plus ventricular regional wall motion abnormality on 2D echocardiography.

Dilated cardiomyopathy is defined by the presence of dilated left ventricle $>5.3 \mathrm{~cm}$ in female, $>5.9 \mathrm{~cm}$ in male [17] (with or without dilatation of the other 3 cardiac chambers) with global systolic and diastolic dysfunctions [18].

Diastolic heart failure was considered when there was normal or slightly reduced ejection fraction despite being a symptomatic patient and meeting the Framingham's criteria mentioned above. Patients were classified according to echocardiological finding of left ventricular ejection fraction to mild (55-45\%), moderate $(44-31 \%)$ and severe $(<30 \%)$ [19].

\section{Results}

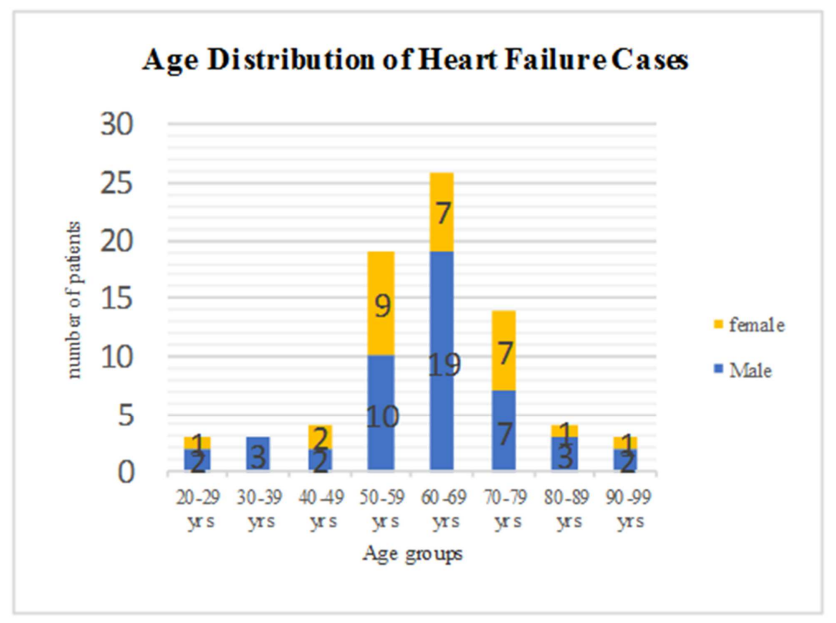

Figure 1. Age and sex distribution of patients in this study.

The sample size was a total of 76 patients complaining of heart failure distributed as 49 males and 27 females that were randomly selected from the admissions to the medical wards and CCU of Al-Yarmook Teaching Hospital and were consented to participate in the study. The age distribution was between 27 and 93 years old, and the mean age is 61.97 years old and the male to female ratio is 1.8: 1 that shows a male predominance, as seen in figure 1 .

By observation of the frequency of the framingham's criteria used as a diagnostic tool for defining heart failure cases, Rales, paroxysmal nocturnal dyspnea and bilateral ankle edema were the most frequently reported; while pleural effusion was the least reported one, as seen in Table 1.

Of the 76 patients of heart failure in this study, 2 patients were diagnosed with heart failure with normal ejection fraction, and the other 74 were diagnosed with reduced left ventricular ejection fraction (LVEF). Severe reduction in left ventricular ejection fraction was found in 27patients $(35.5 \%)$, while moderate reduction was found in 33patients $(43.5 \%)$ and mild reduction in 14 patients (18.4\%), as seen in Table 2.

Table 1. Shows the criteria used with its reporting frequency.

\begin{tabular}{lll}
\hline Criteria & No. of patients & \% of total patients \\
\hline Rales & 67 & $88 \%$ \\
Paroxysmal nocturnal dyspnea & 65 & $85.5 \%$ \\
Bilateral ankle edema & 60 & 78.9 \\
Dyspnea on ordinary exertion & 56 & $73.7 \%$ \\
Nocturnal cough & 55 & $72.4 \%$ \\
Neck vein distention & 54 & $71.1 \%$ \\
Acute pulmonary edema & 52 & $68.4 \%$ \\
Radiographic cardiomegally & 52 & $68.4 \%$ \\
S3 gallop & 35 & $46.1 \%$ \\
Tachycardia (rate of $>120 \mathrm{bpm})$ & 22 & $28.9 \%$ \\
Weight loss of 4.5kg in 5 days & 14 & $18.4 \%$ \\
in response to treatment & 13 & $17.1 \%$ \\
Hepatojugular reflux & 8 & $10.5 \%$ \\
Pleural effusion & &
\end{tabular}

Table 2. Types of heart failure according to LVEF in this study.

\begin{tabular}{lll}
\hline Type of Heart Failure & Frequency & $\mathbf{\%}$ \\
\hline Heart Failure with preserved LVEF & 2 & $2.6 \%$ \\
Mild reduction in LVEF & 14 & $18.4 \%$ \\
Moderate Reduction in LVEF & 33 & $43.5 \%$ \\
Severe Reduction in LVEF & 27 & $35.5 \%$ \\
\hline
\end{tabular}

The study shows that the most prevalent single cause of heart failure is ischemic heart disease with total of 43 patients (30 males and 13 females) and accounts for $56.58 \%$ of the sample size, as in Table 3 and Figure 2 that show the causes of heart failure in this study.

Table 3. Causes of heart failure in study sample.

\begin{tabular}{lllll}
\hline Causes & Males & Females & Total & Mean Age \\
\hline Ischemic & 30 & 13 & 43 & 56.58 \\
Hypertensive heart disease & 4 & 3 & 7 & 9.21 \\
Dilated cardiomyopathy & 4 & 3 & 7 & 9.21 \\
Valvular & 2 & 2 & 4 & 5.26 \\
Anemia & 0 & 1 & 1 & 1.31 \\
Constrictive pericarditis & 0 & 1 & 1 & 1.31 \\
Diabetes Mellitus & 0 & 1 & 1 & 1.31 \\
Mixed Causes & 9 & 3 & 12 & 74 \\
Total & 49 & 27 & 76 & 60 \\
\end{tabular}

The second most prevalent single cause was hypertensive heart disease and the dilated cardiomyopathy with 7 patients 
for each ( 4 males and 3 females for each cause) and account for $9.21 \%$ of the sample size for each cause.

The third single cause in order was valvular heart disease with 4 patients ( 2 males and 2 females) with severe mitral regurgitation and accounts for $5.26 \%$ of the sample size.

The least prevalent single causes were diabetes mellitus
(Diabetes mellitus was found in 37 patients as $48.68 \%$, but was found as the only identified cause in only one patient), anemia (patient was 72 years old with haemoglobin level of $4.3 \mathrm{gm} / \mathrm{dl}$ for $2-3$ months), and constrictive pericarditis (due to tuberculosis) with only one female patient for each cause and account for $1.31 \%$ of the sample size for each single cause.

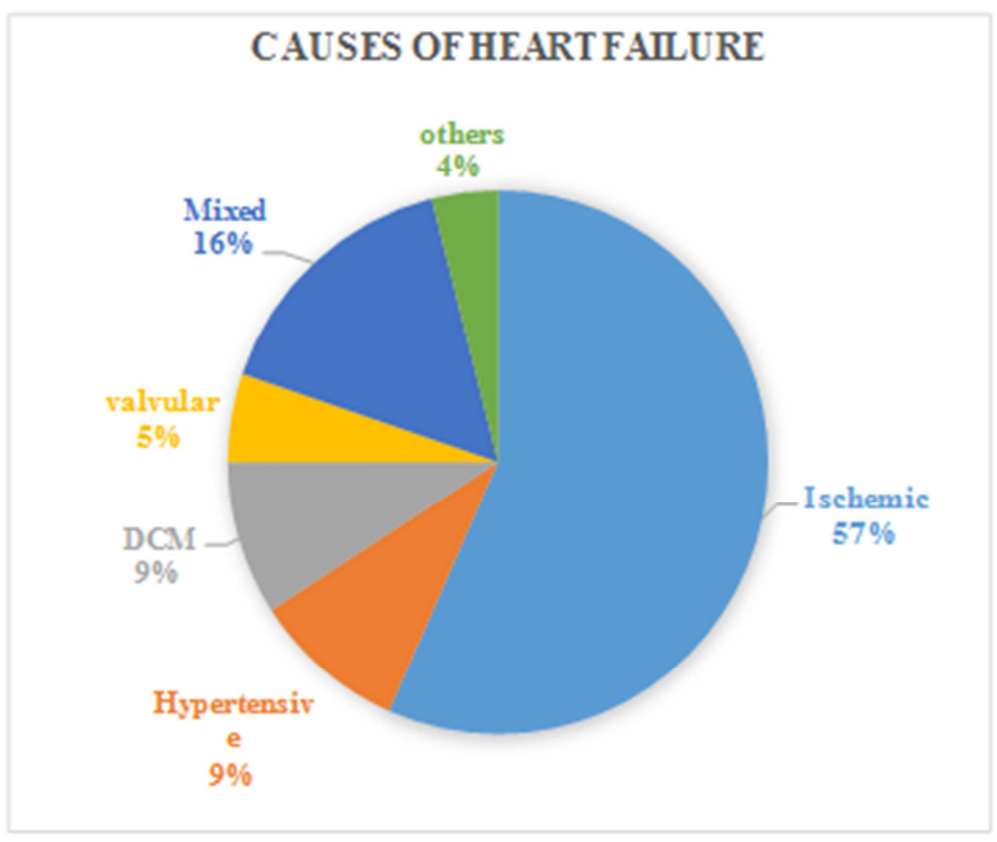

Figure 2. Causes of heart failure in study sample.

A total of 12 patients ( 9 males and 3 females) that accounts for $15.79 \%$ of the sample size had more than one cause of heart failure, as seen Table 4 .

Table 4. Multiple causes of heart failure in study sample

\begin{tabular}{|c|c|c|c|c|}
\hline Causes & Males & Females & Total & $\%$ of total HF patients \\
\hline Ischemic heart disease hypertensive heart disease + diabetes mellitus & 5 & 2 & 7 & $9.21 \%$ \\
\hline Hypertensive heart disease+valvular heart disease & 1 & 1 & 2 & $2.63 \%$ \\
\hline Valvular heart disease + ischemic heart disease + pulmonary hypertension & 1 & 1 & 2 & $2.63 \%$ \\
\hline Valvular heart disease + ischemic heart disease + hypertensive heart disease & 1 & 0 & 1 & $1.31 \%$ \\
\hline Total & 8 & 4 & 12 & $15.79 \%$ \\
\hline
\end{tabular}

\section{Discussion}

The study is cross sectional and descriptive, assessed the causes of heart failure in a randomly selected admitted patients with heart failure to Al-Yarmook Teaching Hospital during one year (2015).

The mean age of the sample taken was 61.97 years old which is slightly higher than that found by Abd Al-Hussain, M. F. which was 57.23 years in Al-Kadhimeya Teaching Hospital [20], and higher than in Accra, Ghana which was 42.3 years [21], but similar to that of USA (61 years) [22] and lower than that of Europe (71.3 years) [23].

It is known that in some non-Western countries, cardiovascular diseases including Heart Failure tend to occur a decade or two earlier than they do in other countries. Nearly half occur before 70 years of age; whereas only one fifth occur so early in the Western countries - a difference attributable to both the earlier occurrence of cardiovascular events and the lower level of clinical care available [24].

In the present study, ischemic heart disease was the most common etiological factor for the developing of heart failure $(56.58 \%)$, which came in concordance with He, J, Ogden, LG, Bazzano, LA, et al study in USA reported that ischemic cardiomyopathy (which is considered to be present in patients with HF who have had an MI or ischemia or, on angiography, severe coronary disease) was the most common cause of HF in developed countries and the incidence of it was more in males than females [25].

While hypertensive heart disease (HHD) and dilated cardiomyopathy (DCM) were the second most common single cause of heart failure in this study as $9.21 \%$ for each cause of the selected patients.

The results of this study in regard to HHD was lower than that of Al-Kadhimeya Teaching hospital (56.6\% and considered as the commonest cause in that study) [20], and This finding 
was lower than that of other studies in Nigeria [26, 27], and in South Africa (the hypertensive heart failure was 33\%) [28].

In regard to DCM, this study showed higher percentage $(9.21 \%)$ than that of Al-Kadhimeya Teaching Hospital (3.6\%) [20], but similar to what was reported by Kamilu M Karaye and Mahmoud U Sani in Nigeria that $10.1 \%$ had dilated cardiomyopathy [29], but lower than Europe that accounts for just under $15 \%$ of cases as stated by Fox KF et al [30].

Valve diseases accounted for $5.6 \%$ in this study, which was slightly less than that found by Cowie MR et al in the United Kingdom which was 7\% [31].

Diabetes mellitus was noted as the only cause in only one patient, $1.31 \%$ in this study, which was lower to what was found in Al-Kadhimeyah Teaching Hospital (8.4\%)[ 20], and lower to what Nichols GA, Hillier, TA, were reported that congestive heart failure was prevalent in $11.8 \%$ of diabetic subjects [32].

Constrictive pericarditis and anemia was noted in this study as $1.31 \%$ for each cause, and I could not find studies that found these causes in their studies.

\section{Conclusion}

The study shows that ischemic heart disease was the commonest single etiological factor that leads to heart failure.

\section{Recommendations}

1. As Heart Failure is a growing health problem, we need more studies in our countries that are larger, multicenter and taking in account the different risk factors associated with heart failure.

2. Primary and secondary preventive measures should be applied and followed up by the health services (primary health care centers, general and specialized hospitals and private clinics and hospitals) to reduce incidence of heart failure.

3. Biomarkers such as BNP and Pro-BNP are essential in diagnosis and follow up of cases with heart failure in hospitals.

\section{References}

[1] Goldman, Schafer; Goldman's Cecil medicine, $24^{\text {th }}$ edition, Elsevier Saunders, 2012: Capter 58, Pages 295-302.

[2] Fauci, Kasper, Hauser, Longo, Jameson, Loscalzo. HARRISON'S Principles of INTERNAL MEDICINE. $18^{\text {th }}$ edition, McGraw Hill Medical, 2012: Chapter 234, P 1901-1916.

[3] STEPHEN J., McPHEE I, MAXINE A., PAPADAKIS, MICHAEL W. RABOW. In CURRENT Medical Diagnosis and Treatment. $5^{\text {th }}$ edition, McGraw Hill LANGE, 2011: P341-351

[4] Nicki R Colledqe, Brian R. Walker, Stuart H. Ralston. Davidsons principles and practice of medicine. $21^{\text {st }}$ edition, Churchill Livingstone, 2010. Chapter 18, P 543- 551.
[5] Kannel WB, Hjortland M, Castelli WP: Role of diabetes in congestive heart failure: the Framingham Study. American Journal of Cardiology 34: 29-34, 1974.

[6] Shindler DM, Kostis JB, Yusuf S, Quinones MA, Pitt B, Stewart D, Pinkett T, Ghali JK, Wilson AC: Diabetes mellitus, a predictor of morbidity and mortality in the Studies of Left Ventricular Dysfunction (SOLVD) Trials and Registry. American Journal of Cardiology 77: 1017 $-1020,1996$.

[7] Poirier P, Garneau C, Marois L, Bogaty P, Dumesnil J-G: Diastolic dysfunction in normotensive men with well-controlled type 2 diabetes: importance of maneuvers in echocardiographic screening for preclinical diabetic cardiomyopathy. Diabetes Care24: 5-10, 2001.

[8] Hibbard, J, Lindheimer, M, Lang, RM. A modified definition for peripartum cardiomyopathy and prognosis based on echocardiography. Obstet Gynecol 1999; 94: 311.

[9] American Heart Association. Heart disease and stroke statistics - 2007 update. Dallas, Texas: American Heart Association; 2007.

[10] Bleumink, GS, Knetsch, AM, Sturkenboom, MC, et al. Quantifying the heart failure epidemic: prevalence, incidence rate, lifetime risk and prognosis of heart failure The Rotterdam Study. European Heart Journal 2004; 25: 1614.

[11] Robert O. Bonow, Douglas L. Mann, Douglas P. Zipes, Peter Libby; Braunwald's HEART DISEASE, $9^{\text {th }}$ edition 2012, Elsevier Saunders. Chapter 24, P 517- 528.

[12] Braunwald E: Biomarkers in heart failure. New England Journal of Medicine 358: 2148, 2008.

[13] http://emedicine.medscape.com/article/163062-overview which is taken from: Framingham Classification: Ho KK, Pinsky JL, Kannel WB, Levy D. The epidemiology of heart failure: the Framingham Study. Journal of American College of Cardiology Oct. 1993; 22 (4 Suppl A): 6A-13A. [Medline].

[14] Glynn, Drake; Hutchison's Clinical Methods, $23^{\text {rd }}$ edition, Saunders Elsevier 2012; Chapter 11: pages 165-179.

[15] Hampton JR; The ECG made easy, seventh edition, Churchil Livingston Elsevier, 2008.

[16] Kaddoura S.; Echo made easy, second edditon, Churchil Livingston Elsevier, 2009

[17] Solomon D.; Bulwer B.; Libby P.; Essential Echocardiography, A Practical Handbook With DVD. 2007 Humana Press Inc. Totowa, New Jersey: 448-451.

[18] Oh JK, Seward JB, Tajik AJ: Cardiomyopathies. In The Echo Manual 3rd edition. Edited by: Oh JK, Seward JB, Tajik AJ. Lippincott Williams \& Wilkins (a Wolters Kluwer business); 2006: 251-273.

[19] James N. Kirkpatrick; Mani A. Vannan; Jagat Narula; Roberto M. Lang. Echocardiography in Heart Failure, Applications, Utility, and New Horizons. Journal of American College of Cardiology. 2007; 50 (5): 381-396. doi: 10.1016/j.jacc.2007. 03. 048.

[20] Abd Al-Hussain; Maitham Fuad, Causes, risk factors and prognostic factors in patients with heart failure admitted to Kadhimeyah Teaching Hospital, 2011. 
[21] Amoah AG, Kallen C: Aetiology of heart failure as seen from a cardiac referral centre in Africa. Cardiology 2000, 93 (1-2): $11-18$.

[22] Howie-Esquivel J, Dracup K: Effect of gender, ethnicity, pulmonary disease and symptom stability on rehospitalization in patients with heart failure. American Journal of Cardiology 2007, 100: 1139-1144.

[23] Lenzen MJ, Rosengren A, Scholte op Reimer W, Follath F, Boersma E, Simoons M, Cleland J, Komajda M: Management of patients with heart failure in clinical practice: differences between men and women. Heart in press. 2007 June 17.

[24] Reddy KS: Cardiovascular diseases in the developing countries: dimensions, determinants, dynamics and directions for public health action. Public Health Nutr 2002, 5: 231-237.

[25] He, J, Ogden, LG, Bazzano, LA, et al. Risk factors for congestive heart failure in US men and women: NHANES I epidemiologic follow-up study. Archives of Internal Medicine 2001; 161: 996.

[26] Familoni OB, Olunuga TO, Olufemi BW: A clinical study of pattern and factors affecting outcome in Nigerian patients with advanced heart failure. Cardiovascular Journal of Africa 2007, 18: 308-311.

[27] Karaye KM, Sani MU, Mijinyawa MS, Borodo MM: Aetiology and echocardiographic features of heart failure with preserved and reduced ejection fraction in Kano Nigeria. Nigerian Journal of Basic and Clinical Sciences 2007, 4 (1-2): 11-17.

[28] Stewart S, Wilkinson D, Hansen C, Vaghela V, Mvungi R, McMurray J, Sliwa K; Predominance of heart failure in the Heart of Soweto Study cohort: emerging challenges for urban African communities. Soweto Cardiovascular Research Unit, Department of Cardiology, Chris Hani Baragwanath Hospital, Bertsham 2013, Johannesburg, South Africa. PMID19029467.

[29] Kamilu M Karaye and Mahmoud U Sani, Factors associated with poor prognosis among patients admitted with heart failure in a Nigerian tertiary medical centre, BMC Cardiovascular Disorders 2008, 8: 16 doi: 10. 1186/1471-2261-8-16.

[30] Fox KF, Cowie MR, Wood DA, Coats AJ, Gibbs JS, Underwood SR, et al. Coronary artery disease as the cause of incident heart failure in the population. European Heart Journal. 2001; 22: 228-36.

[31] Cowie MR, Wood DA, Coats AJ, Thompson SG, Poole-Wilson PA, Suresh V, et al. Incidence and aetiology of heart failure; a population-based study. European Heart Journal. 1999; 20: 421-8.

[32] Nichols, GA, Hillier, TA, Erbey, JR, Brown, JB. Congestive heart failure in type 2 diabetes: Prevalence, incidence, and risk factors. Diabetes Care 2001; 24: 1614. 